\title{
Literatura, política e história na obra de E. P. Thompson
}

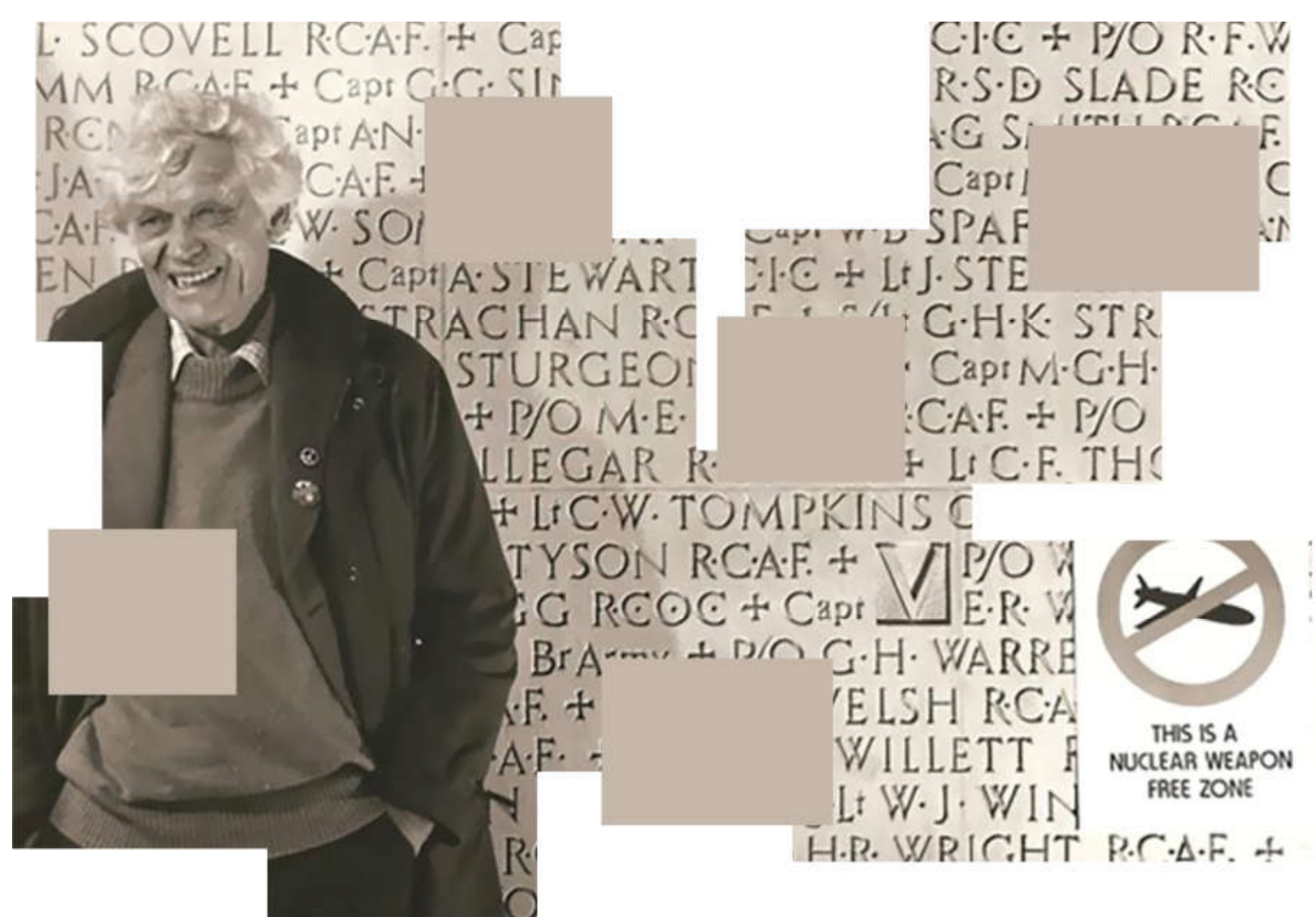

E. P. Thompson, s./d., fotografias, montagem.

\section{Adriano Duarte}

Doutor em História pela Universidade Estadual de Campinas (Unicamp). Professor na Universidade Federal de Santa Catarina (UFSC), onde atua nos cursos de graduação e pós-graduação em História. Pesquisador do CNPq. Coorganizador, entre outros livros, de E. P. Thompson: política e paixão. Chapecó: Argos, 2012.adrianold@uol.com.br 


\title{
Literatura, política e história na obra de E. P. Thompson
}

Literature, politics and history a comment on E. P. Thompson's work

\author{
Adriano Duarte
}

\section{RESUMO}

O objetivo deste estudo é investigar os modos como o historiador marxista britânico E. P. Thompson se apropria da literatura em suas obras historiográficas. Isso implica refletir sobre como ele pensa a relação entre história como disciplina e literatura. Como não poderia deixar de ser, e mesmo que ele não o mencione explicitamente, fica clara sua vinculação à tradição materialista e dialética dos estudos de arte e literatura. Portanto, "forma" e "conteúdo" compõem uma relação unitária de interdeterminação mútua, não podendo, de maneira alguma, ser compreendidas separadamente. Procuramos também destacar quais seriam seus interlocutores e suas fontes de inspiração na relação nem sempre tranquila entre as duas áreas. Por fim, ressalta-se como a literatura é percebida como modo específico de conhecer o mundo.

PALAVRAS-CHAVE: literatura; história; marxismo.

\begin{abstract}
The aim of this study is to investigate the ways in which the British Marxist historian E. P. Thompson approaches literature in his historiographic work. This implies reflecting on how the author thinks about the relationship between history as a discipline and literature. As expected, although Thompson does not explicitly mention it, his link to the materialist and dialectical tradition of art and literature studies is clear. Therefore, "form" and "content" compose a unitary relationship of mutual interdetermination and cannot in any way be understood separately. The study also identifies Thompson's potential interlocutors and his sources of inspiration, in the sometimes unpeaceful relationship between the two areas. Finally, the study emphasizes how literature is perceived as a unique way of getting to know the world.
\end{abstract}

KEYWORDS: literature; history; marxism.

A mediação entre qualquer obra intelectual ou artística e a própria experiência e participação na sociedade nunca é imediata, nunca é direta. Quero dizer, nenhum pintor pode pintar sua experiência política como tal. E se ele tenta fazer isso ele pinta um cartaz, que talvez tenha valor como um cartaz. ${ }^{1}$

Aquele que tiver tido contato com as obras de E. P. Thompson terá notado a importância central que ele atribui à literatura, não apenas para sua argumentação, mas para a própria construção de seus problemas de pesquisa.

\footnotetext{
${ }^{1}$ ABELOVE, Henry (ed.). Visions of history: interviews with E. P. Thompson by MARHO: the radical historians organization. New York. Pantheon, 1976, p. 6.
} 
Na introdução ao livro The essencial of E. P. Thompson, a historiadora Dorothy Thompson escreveu que, embora Edward Thompson houvesse concluído o curso de História, "provavelmente seu primeiro amor foi sempre a literatura, em especial a poesia e o teatro". ${ }^{2}$ Seu primeiro livro publicado, resultado de um longo estudo, foi sobre o poeta, arquiteto e pintor William Morris. ${ }^{3} \mathrm{Em}$ uma entrevista de 1976, Thompson comentou sobre o papel preponderante que a literatura tinha em seu trabalho e em sua formação intelectual: “Eu estava preparando minhas primeiras aulas. Ensinava tanto literatura quanto história e pensava: como posso, para começar, ante uma sala de adultos, muitos deles do movimento operário, falar do significado da literatura em suas vidas. Então comecei a ler Morris... Morris tomou a decisão de que eu teria de apresentá-lo a eles. E no curso dessa apresentação eu levei muito mais a sério a ideia de me tornar historiador".4

Seu companheiro de militância política, o também membro do grupo de historiadores do Partido Comunista Britânico, Christopher Hill, escreveu um inspirado texto, por ocasião de seu falecimento:

Como Karl Marx, Thompson caminhou na contracorrente ao usar a literatura como fonte para a história social e econômica [...] Quem - senão Thompson - citaria Chaucer, Tristram Shandy, Wordsworth, Dickens e os poetas do século XVIII Stephen Duck e Mary Collier em um artigo sobre "Tempo, disciplina de trabalho e capitalismo industrial"? Ele não tinha paciência alguma com o determinismo demográfico e estatístico nem com termos enganosamente "neutros" como "modernização" e "industrialização", usados com o fito de evitar o rude termo "capitalismo". O marxismo de Thompson era inteiramente alheio a dogmas preconcebidos. ${ }^{5}$

Thompson estudou com afinco os escritores e poetas românticos ingleses e um de seus últimos trabalhos, publicado postumamente, foi sobre o poeta William Blake. ${ }^{6}$ Escreveu também uma novela de ficção científica e um grande número de poemas. ${ }^{7}$ Não seria exagero dizer que a literatura emerge em suas obras como uma chave para pensar o mundo com seus conflitos e suas contradições. E o faz, entrelaçando os aspectos econômicos, políticos e sociais, que, de modo geral, são percebidos pelo senso comum como desconectados uns dos outros. Para ele literatura seria um modo de pensar o lugar que as pessoas ocupam no mundo, nas teias complexas que conectam esses diversos aspectos.

Entre 1950 e 1970, Thompson escrevera uma obra erudita a cada dez anos (William Morris, A formação da classe operária inglesa, Senhores e caçadores), e em todas elas "percebia uma grande variedade de formas de expressão literária, não como 'ilustrativas' dos movimentos que estava estudando, mas como

\footnotetext{
2 THOMPSON, Dorothy. The essential E. P. Thompson. New York: New Press, 2001, p. 8.

${ }^{3}$ Ver THOMPSON, E. P. William Morris: romantic to revolutionary. California: Stanford University Press, 1976 [1955].

${ }^{4}$ Idem, in ABELOVE, Henry, op. cit., p. 13.

${ }^{5}$ HILL, Christopher, in THOMPSON, E. P. As peculiaridades dos ingleses e outros artigos. Campinas: Editora da Unicamp, 2001, p. 5.

${ }^{6}$ Ver idem, The romantics: England in a revolutionary age. New York: The New Press, 1997, e idem, Witness against the beast: William Blake and the moral law. New York: The New Press, 1993.

7 Ver idem, The sykaos papers. New York: Pantheon, 1988, e idem, E. P. Thompson collected poems. Newcastle: Bloodaxe, 1999.
} 
parte essencial destes". ${ }^{8}$ Quando descobriu que estava doente, planejou escrever dois estudos. O primeiro, sobre a cultura popular consuetudinária da Inglaterra do século XVIII, e o outro sobre o movimento romântico inglês da década de 1790. O primeiro projeto deu origem à publicação, em 1991, de Costumes em comum. Porém, veio a falecer antes de realizar o segundo projeto que, como menciona Dorothy, "era para ele ainda mais importante". 9

Durante toda a vida, ele havia coletado material e publicado ensaios esparsos sobre os poetas românticos ingleses. Parte dessas anotações deu origem ao livro póstumo: Witness against the beast, sobre o poeta William Blake; outra parte foi reunida pela própria Dorothy no livro The romantics: England in a revolutionary age. Em resumo, a maneira como E. P. Thompson pensava a literatura não está em uma obra específica, está em todas elas, livros, artigos e entrevistas, bem como no modo como ele entendia a própria história como disciplina. Esse é o argumento central deste estudo: para o historiador inglês, história e literatura são dois modos entrelaçados de pensar a agência humana, a literatura é uma fonte para história social, tanto quanto esta é a matéria concreta, que se transmuta naquela forma específica.

O papel atribuído por E. P. Thompson à literatura, como meio para expressão das angústias sobre o presente, como fonte de conhecimento sobre o mundo e sobre o passado, em particular, não foi um caso isolado entre militantes de esquerda na Inglaterra. Já se sugeriu que, em torno da revista Scrutiny, fundada em 1932, e de seu editor, Frank Raymond Leavis, desenvolveu-se um movimento crítico com espírito totalizante que, em certo sentido, teria ocupado o lugar de uma sociologia clássica e de um marxismo nacional. Assim, a fragilidade de ambos na cultura britânica, teria deixado à literatura o papel central como referência crítica, acerca da sociedade moderna. "Com Leavis, a crítica literária inglesa assumiu a responsabilidade pelo julgamento moral e pela asserção metafísica, tornando-se o carro chefe das humanidades".${ }^{10}$ Dessa forma, a literatura foi alçada, na década de 1930, a um patamar "a partir do qual se podia julgar a qualidade de vida da sociedade contemporânea". ${ }^{11}$ A literatura e a crítica literária se constituíram como o principal tribunal a partir do qual se podia, de forma efetiva, avaliar e julgar a constituição de uma sociedade industrial e capitalista, tornando-se assim, referência central para todo compromisso político de esquerda e para a condenação ao status quo.

Desse modo, toda uma geração de jovens estudantes britânicos, com algum grau de insatisfação política e simpatias pela esquerda, na década de 1930, tinha a literatura e a crítica literária como referência das atividades intelectuais centrais, nas quais podia desenvolver e exercitar o espírito crítico. Terry Eagleton explicou a centralidade cultural e política da literatura e da crítica literária, como parte fundamental da identidade e do senso de missão, que teriam marcado a Grã-Bretanha, quando seu desenvolvimento industrial foi progressivamente superado pela concorrência alemã e estadunidense, na

\footnotetext{
${ }^{8}$ THOMPSON, Dorothy, op. cit., p. 7.

${ }^{9}$ Idem, ibidem, p. 8.

${ }^{10}$ ANDERSON, Perry. Components of the national culture. New Left Review, I/50, London, july-august, 1968, p. 58.

11 CEVASCO, Maria Elisa. Para ler Raymond Williams. São Paulo: Paz e Terra, 2001, p. 82.
} 
corrida por novos mercados, culminando na I guerra mundial, em 1914.“O que estava em jogo, nos estudos ingleses, era menos a literatura inglesa do que a literatura inglesa: nossos grandes 'poetas nacionais', Shakespeare e Milton, o senso de tradição nacional 'orgânica' e de uma identidade, que podiam ser criadas nos recrutas pelo estudo das letras humanas". ${ }^{12}$

O impacto social produzido pela perda da centralidade econômica e o consequente declínio de importância internacional, do outrora todo-poderoso império britânico, teria marcado de forma indelével a geração nascida no entre guerras: "Em princípios de 1920, a razão pela qual o inglês deveria ser estudado era desesperadamente obscura: em princípios da década de 1930, a indagação era por que desperdiçar tempo com qualquer outra coisa. O inglês não era apenas uma matéria que valia a pena estudar, mas a atividade mais civilizadora, a essência espiritual da formação social". ${ }^{13}$

Desse modo, as décadas de 1930 e 1940 foram marcadas pela institucionalização do inglês como uma disciplina acadêmica e com destacado papel de contestação social, uma vez que havia se constituído em contraposição ao status quo. Desde sua origem, o estabelecimento de um método interpretativo, que garantisse a validade institucional dessa disciplina, o close reading, foi associado ao nome de F. D. Leavis. Do mesmo modo, e talvez ainda mais importante, a afirmação do sentido de missão social da crítica literária e do espírito anti-establishment se expandiu ligada à revista Scrutiny, criada por ele e "a partir da qual se criticava não apenas a literatura, mas toda a organização social da Inglaterra de então".${ }^{14}$ Nesse contexto, a literatura não era apenas uma disciplina acadêmica ou uma simples área do conhecimento; era o próprio locus em que as questões fundamentais do significado da sociedade inglesa (democracia, indústria, cultura, classe, arte etc.) eram problematizadas, ocupando, portanto, um lugar central tanto na história cultural inglesa, quanto no seu pensamento político e social, no pós-guerra. Por conseguinte, não é surpreendente o envolvimento de E. P. Thompson, e de toda sua geração, com a literatura. Por conseguinte, não é surpreendente o envolvimento de E. P. Thompson e de toda uma geração de jovens de esquerda, que cresceram entre os anos 1930/1940, com a literatura como o meio primordial de reflexão sobre o mundo. Afinal, como ele mesmo observou: "Nossos poetas desenvolveram ocasionalmente a filosofia para além do que fizeram nossos filósofos. Quando eu, que fui formado neste idioma, penso nos problemas de determinismo e livre arbítrio ou de processo social e agência individual, não parto de Spinoza, passando por Marx, Heidegger e Sartre, mas caio em uma meditação de outro tipo, condicionada por uma cultura literária, por entre instâncias, objeções, qualificações, metáforas ambíguas". ${ }^{15}$

A literatura é um meio para o conhecimento sobre a história. Entretanto, supor que a literatura é uma fonte como outra qualquer para o historiador é apenas enunciar um problema. Afinal, o trabalho de qualquer historiador começa com a problematização das peculiaridades da sua fonte. Nesse caso, a

\footnotetext{
12 EAGLETON, Terry. Teoria da literatura: uma introdução. São Paulo: Martins Fontes, 2006, p. 42.

${ }^{13}$ Idem, ibidem, p. 47.

${ }^{14}$ CEVASCO, Maria Elisa, op. cit., p. 93.

${ }^{15}$ Apud MÜLLER, Ricardo Gaspar e DUAYER, Mario (orgs.). A carta aberta de E. P. Thompson a L. Kolakowski e outros ensaios. Florianópolis: Em Debate/UFSC, 2019, p. 43.
} 
pergunta a ser feita é: como a literatura se torna fonte para o historiador E. P. Thompson? Sendo a história a disciplina do contexto e do processo, é bom partir do pressuposto de que: "não existe uma literatura que seja "realmente" grande ou "realmente" alguma coisa, independentemente das maneiras pelas quais essa escrita é tratada dentro de formas específicas de vida social e institucional. ${ }^{16}$ Dito de outro modo, a literatura só revela seu pleno significado, quando pensada no contexto (social, político e econômico) em que é produzida. Mas é importante destacar que a literatura não é lida apenas no contexto em que foi produzida, ela continua a produzir significados que ultrapassam seu tempo de produção e seu contexto. A literatura é do seu tempo e contexto, contudo tem a peculiar capacidade de ultrapassá-los, exprimindo certa autonomia em relação a ambos. ${ }^{17}$ Isso lhe dá uma condição especial, porque exige que a pensemos no seu tempo e contexto, mas também em cada tempo e contexto no qual é lida; o que implica que a pensemos na sua relação própria com as outras obras, que a precederam e com as quais dialoga, uma vez que é resultado das interações do próprio campo literário.

Em todos os dezesseis capítulos de $A$ formação da classe operária inglesa ${ }^{18}$, há referências diretas - e muitas indiretas - à literatura, na forma de poesia, romance, teatro e música. Discorrendo acerca dos mais diversos temas, problemas historiográficos e debates políticos, sociais ou teóricos E. P. Thompson recorre à literatura, ora como inspiração, ora para descrever a complexidade das relações sociais e as elaborações objetivas e subjetivas dos agentes envolvidos, ora como modo de problematizar estruturas de sentimento - otimismo revolucionário, a camaradagem, o pessimismo diante das perseguições políticas, a apostasia e recolhimento à intimidade etc.

No terceiro volume do livro, intitulado "A força dos trabalhadores", o autor se dedica a estudar o movimento dos quebradores de máquinas. O luddismo foi um fenômeno bastante complexo, recorrente em diferentes distritos industriais, nos quais os trabalhadores, com forte apoio das comunidades, destruíam seletivamente as máquinas que aumentavam o desemprego. Seu ciclo mais intenso foi entre os anos de 1811/1813, embora ações dispersas tenham continuado até 1830 . O ápice das ações dos quebradores de máquinas foi o ataque noturno à tecelagem de William Cartwright, em abril de 1812. Esse ataque deu origem a um longo processo, no qual sessenta e quatro mora-

\footnotetext{
16 Ver EAGLETON, Terry, op. cit., p. 306.

17 “O difícil não é compreender que a arte grega e a epopeia se achem ligadas a certas formas do desenvolvimento social, mas que ainda possam proporcionar gozos estéticos e sejam consideradas em certos casos como norma e modelo inacessíveis. Um homem não pode voltar a ser criança sem retornar à infância. Mas não se satisfaz com a ingenuidade da criança e não deve aspirar a reproduzir, em um nível mais elevado, a sinceridade da criança? Não revive na natureza infantil o caráter próprio de cada época em sua verdade natural? Por que a infância social da humanidade, no mais belo de seu florescimento, não deveria exercer uma eterna atração, como uma fase desaparecida para sempre? O encanto que encontramos em sua arte não está em contradição com o caráter primitivo da sociedade em que essa arte se desenvolveu. E, ao contrário, sua produção; poder-se-ia dizer melhor que se acha indissoluvelmente ligada ao fato de que as condições sociais imperfeitas em que nasceu e nas quais forçosamente tinha que nascer não poderiam retornar nunca mais". MARX, Karl. Contribuição à crítica da economia política. São Paulo: Expressão Popular, 2008, p. 271 e 272.

18 THOMPSON, E. P. A formação da classe operária inglesa (3 vs.). Rio de Janeiro: Paz e Terra, 1987.
} 
dores da região foram a julgamento, treze foram condenados à morte e dois à deportação para as colônias. ${ }^{19}$

Thompson assinala que, somente perto das décadas de 1860/1870, as histórias dos envolvidos nas quebras de máquinas começaram a vir à tona. Considerando que os atos mais ousados dos quebradores de máquinas haviam ocorrido por volta de 1811/1812, os envolvidos teriam aproximadamente oitenta ou noventa anos, quando seus relatos foram compilados por historiadores locais com certo grau de simpatia pela sua causa. Ou seja, "como essas obras são a última forma de uma tradição oral secreta, devem ser consideradas como fontes sérias" ${ }^{20} \mathrm{Em}$ diálogo com essas compilações, ele menciona o romance Shirley, de Charlotte Brontë, publicado em 1870, na mesma época em que os depoimentos dos quebradores de máquinas começaram a vir a público. Assim, o romance e os documentos orais comporiam uma tradição interpretativa, com sinais invertidos: os depoimentos expressariam uma profunda simpatia pelos ludditas, enquanto o romance "praticamente todo a favor do outro lado", problematizava o ponto de vista dos proprietários industriais.

Como era seu costume, o historiador britânico assumiu um lado nessa disputa e essa escolha não foi apenas uma questão historiográfica, mas moral e, sobretudo, política. Contudo, esse posicionamento não o impediu de tratar a literatura com o mesmo cuidado dispensado aos documentos orais. Ao longo de toda sua discussão sobre o luddismo, o romance será uma referência central, discutindo detalhadamente um evento específico, o ataque desfechado por mais de 150 pessoas na fábrica de Mr. Gérard Moore, em Rawfolds, no Spen Valley. No romance de Charlote Brontrë, o episódio ocorre no capítulo XIX, intitulado "Uma noite de verão": “O ruído tornou-se nítido. As que o escutavam foram dando conta da sua importância. Não eram passos de dois, de uma dúzia, de vinte homens. Eram passos de centenas deles" ${ }^{21} \mathrm{O}$ ataque dos quebradores de máquinas era esperado. Na verdade, investidas menores já haviam sido realizadas antes, e levaram diversos industriais da região a evitarem a utilização das máquinas que causariam desemprego. Alguns meses antes, o próprio Sr. Moore fora vítima de uma ação dos quebradores. Ele adquirira as tais máquinas, mas antes que elas chegassem à sua fábrica, um grupo de homens mascarados interceptou a carga e as jogou no pântano. Mesmo à beira da falência, o industrial não desistiu e fez uma nova compra de máquinas, mobilizando, desta vez, um grande número de homens para escoltálas até sua fábrica. Mobilizou os juízes do condado, os clérigos e o próprio exército foi posto em prontidão, de modo que todo o condado se dividiu de forma inconciliável.

Em Shirley não temos acesso às opiniões dos quebradores de máquinas. Toda a narrativa está centrada nos valores, propósitos e princípios dos industriais, sempre descritos como inovadores e justos, ainda que, na maior parte do livro, a humanidade de suas ações se deva a decisões femininas e caritativas: “Eles avançam [...] Como a marcha deles é forte! Há disciplina em suas fileiras, não diria coragem, não é o marchar de cem contra dez que mostra essa

\footnotetext{
${ }^{19}$ Ver HOBSBAWM, Eric J. Os trabalhadores: estudos sobre a história do operariado. Rio de Janeiro: Paz e Terra, 1981, cap. 2.

${ }^{20}$ THOMPSON, E. P. A formação da classe operária inglesa, v. III, A força dos trabalhadores, op. cit., p. 59

${ }^{21}$ BRONTË, Charlotte. Shirley. 2. ed. Vitória: Pedra Azul, 2016, p. 220.
} 
qualidade [...] há desespero e sofrimento entre eles. São esses aguilhões que estão empurrando aquelas pessoas à frente". ${ }^{22}$

Como não há, entre os quebradores de máquinas, nenhum valor moral, nenhum princípio norteador, nenhuma ação com sentido justificável, eles só podem ser impelidos pelo instinto, pela dor ou pelo sofrimento. Mas penúria e miséria não são causadas por nenhuma deliberação humana, são parte da própria natureza e como eles não compreendem isso, sua ação é tomada como irracional. Tiros foram disparados pelos arruaceiros. Os defensores tinham esperado esse sinal. Foi o que lhes pareceu mais provável. O edifício ainda há pouco inerte e passivo despertou e o fogo brilhou através da abertura das janelas. Uma descarga de espingardas retumbou pelo vale de Hollow. ${ }^{23}$

Obviamente que o ataque inicial, na descrição de Shirley, partiu dos "arruaceiros". As portas e janelas da fábrica Gerald More foram "despedaçadas", e eles "atiraram para matar" enquanto o destemido empreendedor "apenas os repeliu". Não é difícil entender a razão pela qual Thompson sugeriu que "as limitações de Shirley, evidentemente, residem no tratamento dispensado aos luddistas e seus simpatizantes. Mas a novela continua a ser uma expressão autêntica do mito da classe média". ${ }^{24} \mathrm{O}$ tom geral é simultaneamente de desprezo pelos trabalhadores e de incompreensão das suas ações.

Essa batalha entrou para o folclore popular dos dois lados do confronto, porque explicitou a tomada de posição das autoridades, evidenciando as questões políticas reveladas no conflito de classes. Tornou-se, assim, uma espécie de síntese dos conflitos de classe no contexto das guerras napoleônicas. Partindo dos jornais e dos depoimentos dos envolvidos nos atos de quebra das máquinas, Thompson conta uma história bem diferente da narrada em Shirley. O líder do ataque foi um aparador de tecidos conhecido como George Mellor. Por vinte minutos, os ludditas trocaram tiros com as defesas estabelecidas na fábrica por William Cartwright. Sob fogo cruzado, um grupo de tecelões, armados com machadinhas, tentou derrubar os portões da entrada. Cinco deles ficaram feridos pelos tiros disparados pelos homens entrincheirados na fábrica e dois, mortalmente feridos, ficaram para trás, quando o grupo recuou. Terminado o tiroteio, mosquetes, porretes de metal, machados e lanças ficaram espalhados pelo terreno da fábrica.

Depois de descrever o ataque, recorrendo sobretudo aos jornais da época, ele acrescenta:

Parte do pano de fundo nos é fielmente apresentada em Shirley de Charlotte Brontë. O dono da fábrica, Gérard Moore (baseado em Cartwright), é corretamente mostrado como elemento pertencente à classe média semi-Whig, semi-radical, cujo órgão era o Leeds Mercury - indiferente ou contrário à guerra, ansioso pela remoção de todas as restrições ao comércio, agudamente crítico contra as políticas ministeriais e, principalmente, do Conselho de Ordens. O capelão do exército, Helstone (intimamente baseado no reverendo Hammond Roberson), é um fanático Tory "Igreja-e-Rei" [...] O Sr. Yorke, o squire jacobino-Whig de Charlotte Bronte, dividido entre sua lealdade de classe e sua simpatia pelas queixas populares, também pode ser a reprodução de mais

\footnotetext{
22 Idem, ibidem, p. 225.

${ }^{23}$ Idem.

${ }^{24}$ THOMPSON, E. P. A formação da classe operária inglesa, v. III, op. cit., p. 134.
} 
de um juiz de paz, que se mantiveram estranhamente inativos durante as revoltas luddistas. ${ }^{25}$

O trecho é bastante denso e mostra um profundo conhecimento, não apenas do romance mas, sobretudo, dos acontecimentos do Spen Valley naqueles meses de abril e maio de 1812. Cruzando a narrativa do romance com os depoimentos dos envolvidos e os jornais locais, o historiador não hesita em identificar os personagens do romance com os envolvidos no ataque ao industrial têxtil William Cartwright.

O tiroteio em Rawfolds teria tido como desdobramento uma "reconciliação emocional" entre os grandes donos de fábricas e as autoridades do governo. O interesse econômico trinfou e a lealdade entre os industriais e o governo, contra os operários jacobinos, revelou-se nesse incidente dramático. Essa reconciliação emocional, aprofundou ainda mais o antagonismo entre as classes médias, os industriais e as autoridades governamentais contra os operários fabris. Shirley é uma referência central para E. P. Thompson tornar mais concretos os conflitos ludditas e as divisões sociais que representam. Por um lado, o romance esclarece as outras fontes usadas pelo autor - sobretudo os jornais locais e as narrativas dos antigos participantes - ao dar nomes aos lados do conflito e inseri-los numa trama coerente. Mas o romance não é uma descrição neutra da realidade, a despeito da palavra "reprodução", usada por Thompson, para mencionar como Charlotte Bröntte havia descrito objetivamente o conflito. ${ }^{26}$ Ela assumiu um dos lados, e isso fica claro numa observação da narradora do romance, ponderando sobre os sentimentos e os cálculos do industrial Gérard Moore logo após o conflito:

Ele não queria atacar a massa, talvez um sentimento de justiça lhe dissesse que homens desorientados e mal aconselhados, ainda por cima atiçados por privações, não eram dignos de sua vingança. Contudo, não se sabiam quem eram os chefes do bando. Acreditava-se que era gente de fora, vinda das grandes cidades, muitos deles nem eram membros da classe operária. Eram valdevinos, gente falida, homens que nada tinham a perder. Mr. Moore perseguia-os como um cão persegue a caça. O seu cavalo devia odiar aquela época, pois quase não tinha momentos de descanso. Mr. Moore vivia nas estradas, e os magistrados dos distritos deviam temê-lo, pois eram homens lentos e tímidos. Ele, contudo, forçava-os a vencerem certo medo que os acometia: o medo do assassinato. ${ }^{27}$

Por quase uma centena de páginas, o historiador recorre ao romance de Charlotte Bronttë para preencher as lacunas deixadas pelos jornais e pelos depoimentos e, mais do que isso, a obra literária é uma fonte utilizada para conectar, contrapor e matizar as opiniões e as posições que nem sempre os jornais ou os depoimentos orais esclarecem, atuando, ao mesmo tempo, como elucidação e complemento. Dessa maneira, o romance é profundamente ilustrativo das contradições e dos conflitos que deram forma ao luddismo na região do Rawfolds, no Spen Valley. Sua limitação não é tanto por ter um

${ }^{25}$ Idem, ibidem, p. 133 e 134.

${ }^{26}$ An original, no inglês, talvez mais próximo de retrato. Idem, The making of the English working class. New York: Vintage, New York, 1966, p. 561.

27 BRONTË, Charlotte, op. cit., p. 247. 
lado no conflito, mas advém do fato de que a trama nunca dá voz aos ludditas; e, quando o faz, nos oferece uma leitura parcial e enviesada dos conflitos descritos.

A maneira como E. P. Thompson se apropria do romance Shirley seria um bom exemplo do que ele chama, em outro lugar, de uma "leitura satânica": o romance ideologicamente comprometido e, por isso, parcial na sua descrição do evento é usado para preencher as lacunas dos jornais e dos depoimentos orais. E os jornais, mas sobretudo os depoimentos orais, são usados para destacar a parcialidade ideológica do romance. Mas nem por isso o romance seria menos importante, já que é possível ler em suas páginas os não ditos, os interditos, as entrelinhas; e, sobretudo é possível ver a história em precipitado, como salienta Raymond Williams:

Ainda que seja possível, ao estudar o passado, isolar os aspectos específicos da vida como se fossem únicos e independentes, é óbvio que isso é apenas o modo em que podem ser estudados, não como foram vivenciados. Examinamos cada elemento como um precipitado, mas na experiência vivida do tempo, cada elemento estava em solução, era uma parte inseparável de um todo complexo. E parece ser certo, pela natureza da arte, que o artista retrata essa totalidade, que é na arte, principalmente, que o efeito total da experiência vivida é incorporado e expresso. ${ }^{28}$

\section{Literatura e política}

Para o mais profundo desagrado dos críticos literários, em nenhum momento ao longo das quase novecentas páginas de $A$ formação da classe operária inglesa, o autor se preocupou em discutir o modo como pensa a literatura, nem tampouco a sua especificidade como fonte; salvo engano, ele não o fez em nenhum outro momento de sua obra. Não seria difícil conceber a ideia de que ele poderia receber um parecer negativo se pretendesse publicar seu texto em alguma revista acadêmica da área da literatura e, possivelmente, da história. Poderíamos imaginar um parecerista cuidadoso escrevendo algo como: "falta ao estudo uma reflexão metodológica mais acurada sobre a relação entre literatura e história social. Ao atentar somente para o enredo, o autor negligenciou a análise de questões centrais para a estruturação da trama - como a da perspectiva narrativa que adota e dos padrões estéticos com os quais dialoga. Como resultado, o autor deixou de lado o sentido propriamente literário de sua fonte, tomada pela transparência da história nela narrada, e não chega a aprofundar-se na análise do romance - cuja trama reproduz para demonstrar posições afirmadas de antemão. Frente aos limites e problemas que tal falta de esforço analítico gera para o desenvolvimento de uma proposta tão interessante, recomenda-se uma reelaboração da análise que incorpore mais diretamente a reflexão sobre essa dimensão literária da fonte analisada". Um segundo parecerista, como em geral costumam proceder nossas mais sérias revistas acadêmicas, poderia complementar: "seria importante, em todos esses casos, que o autor se detivesse mais na composição propriamente dita do texto literário do que na paráfrase ou na contextualização histórica, de modo a articular, mais eficazmente, os momentos de análise e interpretação". Ambas as

${ }^{28}$ WILLIAMS, Raymond. Drama from Ibsen to Brecht. London: Hogarth, 1987, p. 18. 
hipóteses seriam bastante plausíveis. E nosso ilustre autor teria seu texto recusado. Mas talvez ele não desanimasse, sobretudo porque não parecia nem um pouco preocupado com a "literalidade da literatura". Ou melhor, a literalidade da literatura (seja lá o que isso queira dizer) não está, para ele, na sua formalidade estética ou textual, mas na incontornável imbricação do mundo social transmutado em forma artística. É esse movimento que produz a especificidade da literatura como fonte e documento. Como era do seu caráter tomar uma posição diante de um confronto e assumir um lado em uma contenda moral e política, poderíamos também imaginar uma conclusão, mais ou menos nesses termos: o que parece estar em disputa na relação entre crítica literária e história social é, por um lado, a delimitação de reservas acadêmicas e a consequente preservação de espaços de publicação, consagração, bolsas de estudo e convites para bancas e congressos. Interdisciplinaridade parece ter se tornado uma referência meramente retórica, cada vez mais vazia, quanto maior é especialização nos distintos campos.

Em nenhum momento da sua discussão sobre Shirley nosso autor se refere ao narrador, como sendo uma entidade distinta da autora. Ao contrário, ele aponta cada personagem como correspondendo a um ator do ataque à fábrica de William Cartwright, e não parece dar importância às demandas acadêmicas sobre sua apropriação direta. E. P. Thompson tinha clareza dessas dificuldades "acadêmicas" e dos limites que impunham ao seu trabalho; "indubitavelmente essa experiência influenciou meu senso de público ao escrever história". ${ }^{29}$ Ele fala aqui especificamente dos anos como professor das escolas noturnas para trabalhadores, a Workers Educational Association, na qual trabalhou por dezessete anos:

Meus livros William Morris e A formação da classe operária inglesa foram escritos tendo em mente o público das classes de adultos ou de militantes políticos, e um pequeno público universitário ao todo. Daí meu descuido com o protocolo acadêmico (sobre o qual, na verdade, eu sabia muito pouco). Eu tenho notado a diferença em minha escrita desde então. A boa recepção de A formação converteu-me em alvo da crítica acadêmica, de modo que, em minha atividade de escrita das duas últimas décadas, também tive em mente esse público crítico. Isso fez minha obra mais lenta e mais autoconsciente, mais cautelosa no julgamento e mais meticulosa em relação ao aparato acadêmico. Talvez a obra tenha ganhado em experiência profissional, mas também perdeu em outros aspectos. ${ }^{30}$

Como bem lembrou John Goode, foi com o objetivo de discutir "o significado da literatura" que Thompson se tornou um historiador, "mas sendo um historiador, ele começou discutindo a biografia de um escritor", William Morris. ${ }^{31}$ Pode parecer paradoxal, mas não é. Como ressalta Goode, em sua obra, literatura e história não aparecem como dois campos separados. Um exemplo estaria na noção de "revolução industrial", com sua ênfase excessiva em capitalismo industrial. É exatamente essa vinculação mecânica que foi in-

\footnotetext{
${ }^{29}$ THOMPSON, E. P. Reflexões sobre Jacob e tudo o mais. História \& Perspectivas, v. 29, n. 55, Uberlândia, jul.-dez. 2016, p. 25.

${ }^{30} \mathrm{Idem}$, ibidem, p. 25 e 26.

${ }^{31}$ GOODE, John. E. P. Thompson and 'the significance of literature'. In: KEAYE, Harvey and MCCLELLAND, Keith. E. P. Thompson: critical perspectives. Philadelphia: Temple University Press, 1990, p. 181.
} 
validada por Thompson, precisamente pelo recurso que ela faz da literatura como resposta ao industrialismo nascente. Resposta que confere coerência e sentido a uma série de valores culturais em disputa, naquele contexto. Outro exemplo estaria nas noções de "agência", como a capacidade de pensar e agir, por meio da razão, em contextos sociais específicos, e de "consciência de classe", como a experiência do conflito precedendo a emergência da classe como tal; uma vez que ambos são fundamentais para se compreender como Thompson pensa a política no romantismo literário.

Ainda segundo Goode, E. P. Thompson faz uso das referências teóricas disponíveis aos estudos literários marxistas dos anos 1950/1960. Ele menciona três, em especial: Raymond Williams, Georgy Lukács e Lucien Goldmann, com os quais Thompson teria mantido estreito diálogo, sobretudo apropriando-se de noções essenciais: "estrutura de sentimento", "realismo" e "consciência possível", respectivamente. Talvez o seu mais importante ganho teórico tenha sido exatamente no cuidado com a contextualização histórica dos poemas, das aladas e dos romances, aos quais se refere. Porque isso nos força a romper com as explicações simplistas que pensam a literatura como um mero jogo anárquico de linguagem. Em resumo, a literatura seria para ele menos um objeto particular e mais um processo de entendimento do mundo. A história como a poesia precisa ser lida transitivamente, como um diálogo. Suas marcas, seus sinais, como os sinais motivadores no texto literário são encobertos/velados pela obscuridade do tempo, mas também da dominação e da assimilação. ${ }^{32}$

No início de uma palestra proferida em Leeds, em 1968, Thompson partiu da constatação de Raymond Willians de que a crise fundamental da cultura, na sociedade Inglesa no século XIX, aparecia de duas maneiras: de um lado, opondo a linguagem da "educação" à linguagem da experiência "ordinária"; de outro, contrapondo a "consciência intelectual" ao "sentimento intenso". Sugeriu então que se recuasse ainda mais no tempo, pois já no século XVIII seria possível observar a enorme distância entre uma cultura letrada e a cultura plebeia. Acrescentou, também, que no século XVII não se encontraria na literatura inglesa um único camponês virtuoso, sendo continuamente descritos como reminiscências de um passado remoto, portanto fora do tempo e deslocados no espaço. Passo a passo, retornaríamos ao jardim do Éden em busca da origem da separação entre educação e vida ordinária. Sua conclusão foi que, para se compreender a literatura que se produziu entre os séculos XVII e XIX, era preciso considerar os significados sociais, políticos e culturais do espaço social, que separava as classes educadas e as classes populares. E o arcabouço cultural da sociedade inglesa desse período era o paternalismo, que "presumia uma diferença qualitativa essencial entre a validade da experiência educada - cultura refinada - e a cultura dos pobres". ${ }^{33}$

Dito de outro modo, a literatura se revela quando compreendemos as contradições da sociedade na qual ela é produzida, porque a literatura não flutua no espaço etéreo separada dessas contradições; ao contrário, a seu modo, ela as problematiza ao colocá-las em solução. Nessa senda, em “Desencan-

\footnotetext{
${ }^{32}$ Idem, ibidem, p. 190.

33 THOMPSON, E. P. Os românticos: a Inglaterra na era revolucionária. Rio de Janeiro: Civilização Brasileira, 2002, p. 17.
} 
to ou apostasia? Um sermão leigo"34, Thompson apontou uma insatisfação com os estudos sobre os poetas ingleses da geração de 1790. Sua objeção residia no fato de que havia uma tendência a separar o poeta do homem de ação política, consequentemente separando a poesia da vida. Ao rejeitar essa separação como forma de interpretação, ele enfatizava que esse afastamento era a causa de inúmeros mal-entendidos da crítica literária e da consequente pouca atenção dada "à verdadeira experiência histórica vivida". Assim, reafirmava que essa ligação - ou seja, a reconexão entre poesia e política, entre história e literatura, entre a poesia e o mundo material concreto no qual ela era produzida - era central para uma abordagem materialista da literatura. Sem isso, a atenção do crítico se afastava para uma "sucessão de ideias" desarticuladas das condições concretas em que eram produzidas.

Dois aspectos aqui são fundamentais: primeiro, a centralidade da noção de "experiência", como a maneira pela qual se vincula a ação humana às condições materiais em que essas ações são produzidas; segundo, a importância fundamental atribuída às condições materiais concretas dessa experiência, como determinantes para um entendimento do significado da poesia - bem como, pode-se inferir, da arte em geral. Esse princípio, simultaneamente teórico e metodológico, está contido na fórmula: “quando tentamos definir a natureza romântica, é sempre útil procurar saber a que essa natureza se opõe, o que não é natureza" ${ }^{35}$ Foi a experiência concreta - como síntese de múltiplas determinações - que forneceu o conteúdo sócio-histórico à geração de poetas românticos ingleses, libertando-os da rígida estrutura de sensibilidade do paternalismo, na qual a vida interior dos pobres só podia aparecer como o pitoresco e o exótico; e em relação à qual o sentimento generalizado era a condescendência. Foi o arrebatador impulso da liberdade, igualdade e fraternidade jacobina, essa nova "estrutura de sentimentos", que esgarçou a tessitura do paternalismo. Afinal, esse fora o momento "em que a cultura tradicional foi desafiada, quando todas as convenções foram questionadas e as grandes esperanças humanistas estavam no além-mar, mas também quando a experiência perspicaz mostrava que as posições dos philosophes eram inadequadas -, é exatamente no meio desse conflito que o grande impulso romântico alcançou a maturidade". 36

Destarte, o impulso criativo dos poetas românticos emerge da contradição entre a tradição paternalista, por um lado, e as possibilidades anunciadas pela "consciência possível" de liberdade, razão, igualdade e fraternidade, de outro. O impulso criativo foi continuamente alimentado por essa tensão. Quando a tensão diminuiu, o impulso também recuou e deu margem ao desencanto, mas não há nada nele que seja hostil à poesia. Quando a repressão política se intensificou e a perseguição se tornou recorrente a apostasia emergiu como "um fracasso moral e um fracasso imaginativo". ${ }^{37}$

Portanto, a chave para se compreender a poesia romântica da geração de 1790, bem como a literatura e a arte em geral, é sempre partir do modo como os homens estão no mundo, como reagem às forças em jogo, como res-

\footnotetext{
${ }^{34}$ Idem, ibidem, cap. "Desencanto ou apostasia? Um sermão leigo".

${ }^{35} \mathrm{Idem}$, ibidem, p. 53.

${ }^{36}$ Idem, ibidem, p. 55 e 56.

${ }^{37}$ Idem, ibidem, p. 56.
} 
pondem às condições econômicas, políticas e sociais com que se deparam, pois suas respostas fundamentam as escolhas formais e estilísticas, que são os modos de organizar e dar sentido literário às suas experiências vividas ou herdadas. Toda sua interpretação do significado da poesia é no sentido de reconectar a educação com as experiências ordinárias da vida, a consciência intelectual e o sentimento. Em resumo, a literatura nos permitiria refazer essa conexão, quando a tomamos como parte intrínseca, como estruturante, do próprio processo histórico.

Refletindo acerca do período entre o verão de 1797 e a primavera de 1798, Thompson sugere que haveria ali a concentração de "um intenso sentimento de cordialidade, uma intensidade de comunicação, uma ausência de reserva" 38 entre os poetas românticos William Wordsworth, John Thelwall, Samuel Taylor Coleridge, envolvidos com o jacobinismo. Esse clima é expresso em poemas como um de John Thelwall, transcrito por Thompson e que, conforme sua avaliação, "está entre os três ou quatro melhores já feitos por ele":

\section{[...] E seria agradável,}

Quando terminasse todo o trabalho, estudar,

E o esforço literário, tivesse sido pago,

Alternadamente, cada um sentar no caramanchão do outro,

$\mathrm{Na}$ suave estação estival; ou, quando, triste,

A rajada do inverno tivesse arrancado a sombra das folhas,

Em torno da lareira flamejante, sociáveis e alegres,

Compartilhar nossas refeições frugais, e da taça

Da bebida fervilhante, feita em casa: aos nossos lados

Tia Sara, e minha Susan, e, talvez,

O proprietário pensativo de Alfoxden, e a criada

De olho fogoso, que, com amor fraternal,

Ameniza-lhe a solidão.... ${ }^{39}$

Mas também teria sido o momento de uma incessante vigilância policial, quando a repressão se abateu ferozmente sobre o que ainda restava do jacobinismo britânico, e o início de um grande recolhimento e consequente confusão, que teriam originado um grande desencanto coletivo, chegando, ao que sugere o título de seu estudo, à apostasia. Num primeiro momento, os poetas jacobinos haviam "sido acuados para grupos de sobrevivência, pequenos e pessoais". ${ }^{40}$ Foram isolados, vigiados e perseguidos, enquanto o governo esvaziava quaisquer tentativas de aproximação entre os radicais ingleses e franceses. É essa condição social e política que esclarece não apenas o conteúdo, mas a forma dos seus escritos: construídos como diálogos pessoais com um amigo íntimo, porém ausente, como no longo poema autobiográfico "Prelude", escrito por William Wordsworth. Ou como no longo monólogo interior, expressão do homem isolado, vigiado, perseguido, como nos "livros proféticos" de William Blake:

\footnotetext{
${ }^{38}$ Idem, ibidem, p. 62.

${ }^{39}$ Idem, ibidem, p. 69 e 70.

${ }^{40}$ Idem, ibidem, p. 72.
} 
Ah! Deixem que eu, lá longe em algum vale perdido,

Construa minha cabana baixa; e que ela seja feliz,

Meu Samuel! Perto da tua, que eu possa muitas vezes

Compartilhar a tua doce conversa, meu mais amado dos amigos!

Amado muito antes de conhecido: pois afinidades

Ligavam, embora a muita distância, nossas almas irmãs... ${ }^{41}$

Conteúdo social e forma literária emergem entrelaçados numa relação de determinação recíproca. Não pode haver uma fatura crítica razoável se contar apenas com uma análise conteudista; nem, muito menos, com uma avaliação puramente formal. Ou seja, na perspectiva do historiador E. P. Thompson apresentada até aqui, a questão central é a relação entre forma literária e o conteúdo social. Dito de outro modo, entre literatura e sociedade, relação que o texto literário explicita. Sob esse prisma, a literatura é tomada essencialmente como uma reorganização "do mundo em termos de arte; a tarefa do escritor de ficção é construir um sistema arbitrário de objetos, atos, ocorrências, sentimentos, representados ficcionalmente conforme um princípio de organização adequado à situação literária dada, que mantém a estrutura da obra". ${ }^{42}$

Texto e contexto, literatura e sociedade se fundem dialeticamente: "o externo (no caso, o social) importa não como causa, nem como significado. Mas como elemento que desempenha um certo papel na constituição da estrutura, tornando-se, portanto, interno" ${ }^{43}$ Problematizar o modo especificamente literário da expressão do contexto sócio-histórico me parece ser a maneira mais produtiva de pensar a difícil relação entre história e literatura. Como aponta Roberto Schwarz,

Que a literatura faça parte da sociedade, ou que se conheça a literatura através da sociedade e a sociedade através da literatura, são teses capitais do século XIX, sem as quais, aliás, a importância especificamente moderna da literatura fica incompreensível. Elas estão na origem de visões geniais e dos piores calhamaços. Em seguida se tornaram lugar-comum que sustenta a historiografia literária convencional. Dentro desse quadro, o traço que distingue a crítica dialética, e que a torna especial, é que ela desbanaliza e tensiona essa inerência recíproca dos polos, sem suprimi-la. O que for óbvio, para ela não vale a pena. Se não for preciso adivinhar, pesquisar, construir, recusar as aparências, consubstanciar intuições difíceis, a crítica não é crítica. Para a crítica dialética o trabalho da figuração literária é um modo substantivo de pensamento, uma via sui generis de pesquisa, que aspira à consistência e tem exigência máxima. O resultado não é a simples reiteração da experiência cotidiana, a cuja prepotência se opõe, cujas contradições explicita, cujas tendências acentua, com decisivo resultado de clarificação. Em suma, em termos de método, o ponto de partida está na configuração da obra, com as luzes que the são próprias, e não na sociedade. ${ }^{44}$

Como sugeriu Theodor Adorno, "o conteúdo de verdade das obras de arte funde-se com o seu conteúdo crítico", conteúdo que não se encontra "fora

\footnotetext{
${ }^{41}$ Idem, ibidem, p. 69.

${ }^{42}$ CANDIDO, Antonio. Literatura e sociedade: estudos de teoria e história da literatura. 8. ed. São Paulo: T. A. Queiroz, 2002, p. 179.

${ }^{43}$ Idem.

${ }^{44}$ SCHWARZ, Roberto. Na periferia do capitalismo (entrevista). In: Martinha versus Lucrécia. São Paulo: Companhia das Letras, 2012, p. 281.
} 
da história, mas constitui a sua cristalização nas obras". ${ }^{45}$ Assim, "a arte nega as determinações categorialmente impressas na empiria e, no entanto, encerra na sua própria substância um ente empírico. Embora se oponha à empiria através do momento da forma - e a mediação da forma e do conteúdo não deve conceber-se sem a sua distinção -, importa, porém, em certa medida e geralmente, buscar a mediação no fato de a forma estética ser conteúdo sedimentado". ${ }^{46}$ É esse o procedimento teórico e metodológico de E. P. Thompson na sua apropriação da literatura como fonte e documento, mesmo que não o assuma explicitamente. Essa é a chave de uma leitura materialista e dialética que ele praticou, como parte do que chamava "uma tradição marxista".

Artigo recebido em 15 de fevereiro de 2021. Aprovado em 10 de março de 2021.

${ }^{45}$ ADORNO, Theodor. Teoria estética. Lisboa: Edições 70, 1970, p. 154.

${ }^{46}$ Idem, ibidem, p. 17. 